Vietnam Journal of Mechanics, VAST, Vol.34, No. 1 (2012), pp. $19-25$

\title{
EXPERIMENTAL STUDY ON YOUNG'S MODULUS E OF A POLYMER COMPOSITE REINFORCED BY NANO TITANIUM DIOXIDE PARTICLES
}

\author{
Nguyen Dinh Duc ${ }^{1}$, Dinh Khac Minh ${ }^{2}$ \\ ${ }^{1}$ University of Engineering and Technology, $V N U$ \\ ${ }^{2}$ Shipbuilding Science and Technology Institute
}

\begin{abstract}
There are many formulas proposed by different authors in order to determine elastic modules for composite filler particles. This article aims to present the experiment's results and to review some formulas for determining Young's modulus of elasticity E of the polyester filler titanium dioxide particles composite. The results showed that there was a relatively good fit between theory and practice of some formulas.
\end{abstract}

Keywords: Composite, polyester, titanium dioxide particles $\mathrm{TiO}_{2}$, Young's modulus E.

\section{INTRODUCTION}

Composite material consists of two or more distinct components to obtain a new material with better properties. Such components include matrix material and filled materials including fiber, fabric, particles, and so on. The matrix material aims to ensure the linkages among all the composite components, which will resist all external acting on the composite including heating, physical, and chemical loads, while the filled components are used to improve the mechanical properties (stiffness and strength) of the composite $[1,2,3]$. The composite reinforcement components typically are composed of fiber, fabric, or particles. The fibers and fabrics increase the bearing capacity of the composite structure, while the particles often reduce crack, plastic deformation and increase the waterproofing capacity. Hence, the combination of fiber and particles in the composite material is able to make the composite product more perfect and meet the requirements of modern technology $[4,5,6,7]$.

Recently, the reinforce of polymers using piezoelectric particles, ferromagnetic particles, titanium dioxide particles,... not only increases the strength of the material but also makes the composite product own its new physical characteristics. Therefore, the authors are interested in studying the polymer composites reinforced by additional particles in this study $[4,5,7]$.

When using composite materials, we need to determine their mechanical and physical properties, and also to find out their elastic module and Poisson's ratio that are the most significant mechanical properties of composite material. Composite with filled particles is often considered as an isotropic homogeneous elastic material, and it has two 
independent elastic constants, including Young's modulus (E) and Poisson's ratio. At present, many authors have proposed the different formulas to determine Young's modulus $\mathrm{E}$ of composites. In the article [5], the authors empirically tested the modulus $\mathrm{E}$ to the polystyrene and titanium dioxide particles composite. This article presents the results of an experimental testing for determining the Young's modulus of the polyester and titanium dioxide particles composite.

\section{DETERMINATION OF YOUNG'S MODULUS OF COMPOSITE MATERIALS}

Nowadays, many authors have stated formulas for determining Young's modulus of the particles composite $[4,5,6]$.

We can summarize that currently there are three approaches for determining the elastic modules of composite material including experiments, inductive methods, and using mechanical models. The details of each approach are presented as the following:

- The experimental approach. The advantage of this method is able to determine accurately the elastic modulus of composite. However, the main disadvantage of this method is that it does not reflect the influence of material composition on the composite material because composite is material comprised a variety of components.

- The inductive methods. Based on the repeated experiments, the authors can predict the rules and give the formula for determining the elastic module $\mathrm{E}$ of the material. This approach is used more effectively with the materials which are surveyed, but less suitable for other materials.

- Using mechanical models. In the mechanical model, the particles are usually the spherical particles. The advantage of this method is easy to determine the relationship between the components of composite materials and elastic modulus. Therefore, we can also calculate and predict their values which are a basis for calculating and optimizing the design of the characteristics for new material. However, the results calculated by the mechanical model depend on the model of calculation and such results may vary according to different composites.

There are some popular formulas for determining Young's modulus of the composite filler particles as follows:

i) Einstein and Guth [1]:

$$
E_{E}=E_{m}\left(1+1,25 \xi_{a}\right) .
$$

ii) Guth [2]:

$$
E_{G}=E_{m}\left(1+2,5 \xi_{a}+14,1 \xi_{a}^{2}\right)
$$

iii) Kerner [3]:

$$
E_{K}=E_{m}\left[1+\frac{15 \xi_{a}\left(1-\nu_{m}\right)}{\left(1-\xi_{a}\right)\left(8-10 \nu_{m}\right)}\right],
$$

where $\nu_{m}$ Poisson's ratio of matrix material.

iv) Quemeda [5]:

$$
E_{Q}=E_{m} \cdot \frac{1}{\left(1-0,5 k \xi_{a}^{2}\right)},
$$


with $k=$ const $(\mathrm{k}=0.25)$.

v) Thomas [5]:

$$
E_{T}=E_{m}\left(1+2,5 \xi_{a}+10,05 \xi_{a}^{2}+0,00273 \exp \left(16,6 \xi_{a}\right)\right) .
$$

vi) Kristensen [6]:

where

$$
E=\frac{9 \bar{K}_{E} \bar{G}_{E}}{3 \bar{K}_{E}+\bar{G}_{E}}
$$

$$
\begin{aligned}
& \bar{G}_{E}=G_{m}\left[1-\frac{15\left(1-\nu_{m}\right)\left(1-\frac{G_{a}}{G_{m}}\right) \xi_{a}^{\prime}}{7-5 \nu_{m}+\left(8-10 \nu_{m}\right) \frac{G_{a}}{G_{m}}}\right], \\
& \bar{K}_{E}=K_{m}+\frac{\left(K_{a}-K_{m}\right) \xi_{a}^{\prime}}{1+\left(K_{a}-K_{m}\right)\left(K_{m}+\frac{4 G_{m}}{3}\right)^{-1}}
\end{aligned}
$$

vii) Vanin - Nguyen Dinh Duc [4, 7]:

$$
E=\frac{9 \bar{K} \bar{G}}{3 \bar{K}+\bar{G}}
$$

where

here

$$
\begin{aligned}
\bar{K} & =K_{m} \frac{1+4 \xi_{a}^{\prime} G_{m} L\left(3 K_{m}\right)^{-1}}{1-4 \xi_{a}^{\prime} G_{m} L\left(3 K_{m}\right)^{-1}} \\
\bar{G} & =\frac{1-\xi_{a}^{\prime}\left(7-5 \nu_{m}\right) H}{1+\xi_{a}^{\prime}\left(8-10 \nu_{m}\right) H}
\end{aligned}
$$

$$
L=\frac{K_{a}-K_{m}}{K_{a}+\frac{4 G_{m}}{3}}, \quad H=\frac{\frac{G_{m}}{G_{a}}-1}{8-10 \nu_{m}+\left(7-5 \nu_{m}\right) \frac{G_{m}}{G_{a}}} .
$$

In the equations (1) - (9), the terms $E_{m}, \nu_{m}, K_{m} G_{m}, G$ are, respectively, Young's modulus, the Poisson's ratio, volume module and shear modulus of matrix material. The subscript " $a$ " belongs to the particle.

In formulas (1) - (5), $\xi_{a}$ is the mass ratio of particle. Other while, $\xi_{a}^{\prime}$ in the formula (6) and (8)-(9) is volume ratio of particle. In our formula (8)-(9) [4, 7], we have taken into account the interaction between particle and matrix material.

The values $\xi_{a}^{\prime}$ and $\xi_{a}$ is according to volume ratio and mass ratio, which are determined as below:

$$
\begin{aligned}
& \xi_{a}^{\prime}=\frac{V_{a}}{V_{a}+V_{m}}=\frac{\frac{m_{a}}{\rho_{a}}}{\frac{m_{a}}{\rho_{a}}+\frac{m_{m}}{\rho_{m}}}=\frac{1}{1+\frac{m_{m} \rho_{a}}{\rho_{m} m_{a}}}=\frac{1}{1+\frac{\rho_{a}}{\rho_{m}}\left(\frac{1}{\xi_{a}}-1\right)}=\frac{\rho_{m}}{\rho_{m}+\rho_{a}\left(\frac{1}{\xi_{a}}-1\right)} \\
& \xi_{a}=\frac{m_{a}}{m_{m}+m_{a}}, \quad \frac{1}{\xi_{a}}=1+\frac{m_{m}}{m_{a}} \Rightarrow \frac{m_{m}}{m_{a}}=\frac{1}{\xi_{a}}-1
\end{aligned}
$$


We have the correlation between the volume ratio and mass ratio as below:

$$
\xi_{a}^{\prime}=\frac{V_{a}}{V_{a}+V_{m}}=\frac{\rho_{m}}{\rho_{m}+\rho_{a} \frac{m_{m}}{m_{a}}}
$$

where $V_{m}, V_{a}$ are volumes of matrix polyester and Titanium oxide, respectively.

$\rho_{m}$ and $\rho_{a}$ are densities of matrix polyester and Titanium oxide, respectively.

\section{EXPERIMENT AND RESULTS}

\subsection{Making the samples}

To verify Young's modulus for 3-phase composite, we tested the samples made of polyester AKAVINA and titanium dioxide, having properties shown in Table 1.

Table 1. Properties of each composite component

\begin{tabular}{|l|c|c|}
\hline Composite components & Young's modulus E & Poisson's ratio $\nu$ \\
\hline Matrix polyester AKAVINA (Vietnam) & $1,43 \mathrm{GPa}$ & 0.345 \\
\hline Titanium dioxide $\mathrm{TiO}_{2}$ (Australia) & $5,58 \mathrm{GPa}$ & 0.20 \\
\hline
\end{tabular}

The experiments were done at the Laboratory of Shipbuilding Technology Institute, Nha Trang University. The samples were made according to Vietnamese standard code: TCVN 6282:2008 [8]:

- Add titanium dioxide particles to polyester: using magnetic mixer, the needed time for the mixture to be well blended is 15 minutes. The mixture then is poured into a smooth-wall mould. During the hardening process, a vacuum pump is used to remove gas and dust.

- Ambient properties: room's temperature was $\left(20 \pm 5^{0} \mathrm{C}\right)$, humidity was $65 \% \pm 20 \%$.

- Preliminary checking before test: the mould is removed after 24 hours, the samples have smooth surface and uniform thickness and no void.
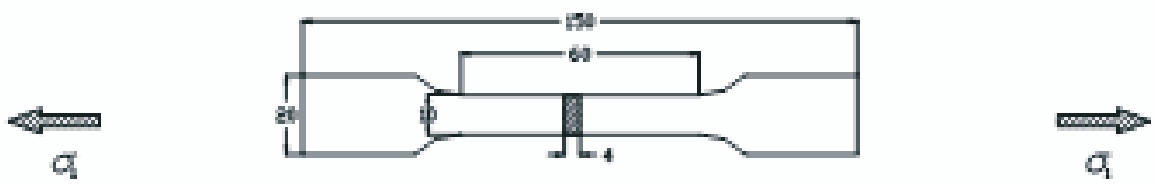

Fig. 1. Dimensions of the composite sample

The dimension of the sample is given in Fig. 1. 


\subsection{Property tests}

The tests were done on HOUNSFEILD H50K-S tester whose maximum tensile load of 50000N (Fig. 2) using BS EN ISO 527-1: 1997 method.

We experimented three cases, when the volume ratios of titanium oxide particles are $5 \%, 10 \%$ and $15 \%$ (the corresponding mass ratio is $18 \%, 31 \%$ and $42 \%$ ). Seven samples are used for each case.

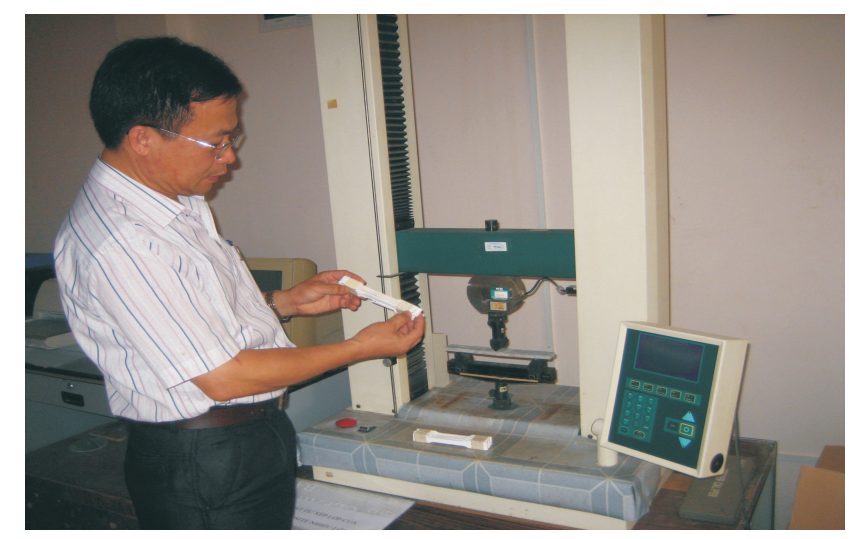

Fig. 2. HOUNSFEILD H50K-S Tester

- Ambient properties: room's temperature was $\left(20 \pm 5^{0} \mathrm{C}\right)$, humidity was $65 \% \pm 20 \%$.

- Test speed: $1 \mathrm{~mm} /$ minute

- Load range: $20000 \mathrm{~N}$

- Extension range: $8.000 \mathrm{~mm}$

- Gauge length: 50mm

\subsection{Post processing}

The tensile strength is calculated as

$$
\sigma_{k}=\frac{P}{F}\left(\mathrm{~N} / \mathrm{mm}^{2}\right)
$$

here $P$ is the ultimate tensile load and $F$ is the cross area of the sample.

The expression for the composite's Young's modulus $E$ is

$$
E=\frac{l}{F}\left(\frac{\Delta P}{\Delta l}\right)\left(\mathrm{N} / \mathrm{mm}^{2}\right)
$$

here, $l$ is the distance between the clamps, $\Delta \mathrm{P}$ is the variation of load and $\Delta \mathrm{l}$ is the absolute elongation.

Since the number of samples is not large and the deviation between the tests is small, the final result will be calculated as the arithmetic mean of all the tests' results,

$$
x_{\text {average }}=\frac{x_{1}+x_{2}+x_{3}+x_{4}+x_{5}+x_{6}+x_{7}}{7}
$$


The theoretical results for Young's modulus with different particle volume ratios are given in Table 2. The columns (3), (6) and (9) are correspond to the three experimental values of the particle mass ratio $0.18 ; 0.31 ; 0.42$. The experimental results are included.

Table 2. The theoretical results and experimental results for YoungÒs modulus E with different particle volume ratio

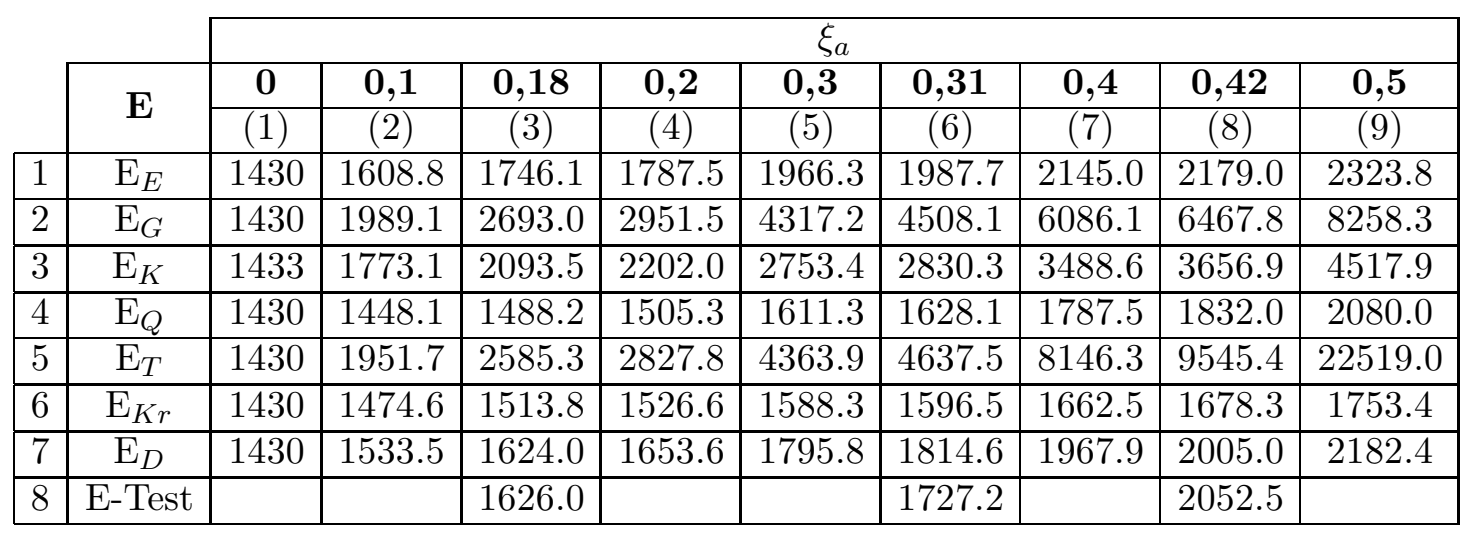

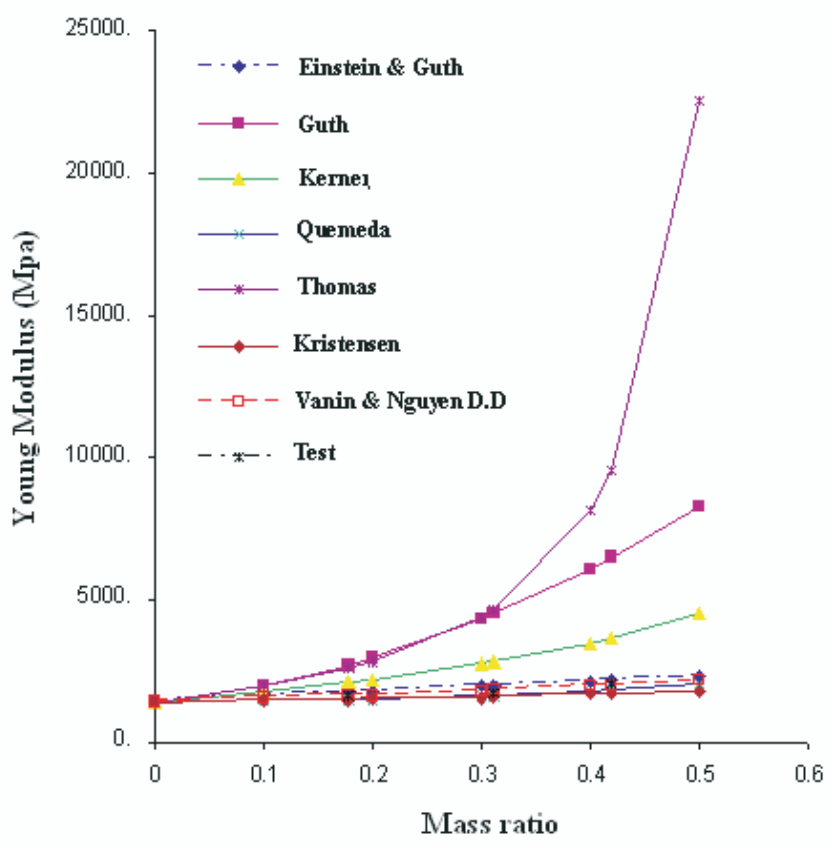

Fig. 3. The experiment results of Young's modulus of the polyester/titanium dioxide composite for different particle mass ratios 
Comparisons between the experimental results and the results calculated from formulas (1) - (6) and (8) of Young's modulus of the polyester composite reinforced with titanium dioxide particles are shown in Table 2 and Fig. 3.

\section{CONCLUSION}

From the theoretical and experimental results represented in Table 2 and Fig. 3, we have some conclusions for the experiment of polyester-titanium dioxides composite as below:

When the ratio of particles are small (less than 20\%), the calculated results of elastic module E according to the formulas from (1) to (8)-(9) are quite consistent with the experiment results. The calculated results according to the formulas of Guth (2), Kerner (3) Thomas (5) are different from the experiment results when the ratio of particles is greater than $20 \%$.

The formulas for calculation of the Young's modulus values of composite of Einstein \& Guth (1), Quemada (4), Kristensen (6) and Vanin - Nguyen Dinh Duc (8)-(9) are consistent with the experimental results.

In all above formulas for calculation of the Young's modulus values of composite, the formula (8)-(9) is the best consistent with the experiment. In the formula (8)-(9), the authors considered the interaction between particle and matrix polyester.

The authors would like to thank the Laboratory of Technology, Shipbuilding Technology Institute of Nha Trang University for its assistance on experiments.

\section{REFERENCES}

[1] L. E. Nielson, Mechanics properties of Polymers and Composites, Marcel Dekker, New York, 2 (1974).

[2] J. A. Manson, L. H. Sperling, Polymer Blends and Composite, Plenum, New York, (1976).

[3] Shackelford, James F. et al, Materials Science and Engineering Handbook, CRC Press LLC, (2001).

[4] Vanin G. A., Nguyen Dinh Duc, The theory of spherofibrous composite.1: The input relations, hypothesis and models, J. Mechanics of composite materials, 32(3) (1996) 291 - 305.

[5] J. A. P. Selvin, Joseph Kuruvilla, Thomas Sabu, Mechanical properties of titanium dioxidefilled polystyrene micro composites, J. Materials letters, 58 (2004) 281 - 289.

[6] R. M. Christensen, Mechanics of composite materials, Joln Wiley and Sons Inc. New York, (1979).

[7] Nguyen Dinh Duc, Mechanics of nano-composite materials, Journal of Science- MathematicPhysics, Vietnam National University, Hanoi, 19(4) (2003) 13 - 18.

[8] Vietnamese standards code TCVN 6282:2008 for testing and manufacturing ship made of composite polymer reinforced by glass fibers, Transportation Publishing House, Hanoi, (2008).

Received January 19, 2011 